\title{
高速液体クロマトグラフィーによるキョウニン水中の
} マンデルニトリルの定量

宮地澄子, 森田多賀史, 岡本光美, 二村昭辰, 後藤滋夫, 玉置誠吾 岥皋県立多治見病院薬剤部*

\section{High-Performance Liquid Chromatographic Determination of Mandelonitrile in Apricot Kernel Water}

\author{
SUMIKo MIYACHI, TAKASHI MORITA, Mitsuyoshi OKAMOTO, \\ AKIYoshi Futamura, Shigeo Goto, Seigo TAMAoKI \\ Department of Pharmacy, Gifu Prefectural Tajimi Hospital*
}

(Received December 25, 1986)

\begin{abstract}
Mandelonitrile in Apricot Kernel Water was studied by high-performance liquid chromatography using an octadecyl bonded stationary phase. According to the Kawai method, $0.5 \mathrm{ml}$ of Apricot Kernel Water is treated with $0.3 \mathrm{ml}$ of $1 \%$ hydroxylamine hydrochloride solution, which react with free benzaldehyde. After an excess of hydroxylamine is removed by adding $0.2 \mathrm{ml}$ of acetone, the mixture is treated with $0.3 \mathrm{ml}$ of $10 \%$ ammonia solution. And then, the aqueous solution is saturated with $\mathrm{NaCl}$, and the benzaldehyde produced corresponding to mandelonitrile is extracted with $2 \mathrm{ml}$ of ethl acetate containing $0.6 \mathrm{mg}$ of $\alpha$-(o-tolylazo)- $\beta$-naphthylamine as an internal standard. This method was applied to analysis of a colored preparation composed of Apricot Kernel Water, Senega Syrup and M.Verdau I (3:5:5) or Apricot Kernel Water, Liquid Brocin and M. Verdau I (3:5:10). With this method, the amount of benzaldehyde produced corresponding to mandelonitrile was determined within $1.68 \%$ error over the range from $0.5-5.0 \mu \mathrm{g} / \mathrm{ml}$.
\end{abstract}

Keywords_-Apricot Kernel Water; benzaldehyde; high-performance liquid chromatography ; mandelonitrile

\section{緒}

キョウニン水は鎮咳去疢薬として日本薬局方に収載さ れ，その有効成分はアミグダリンがキョウニン蛋白中, 酵素エムルシンの作用により水の存在のもとに分解して 生じるマンデルニトリル（Man）であると考えられてい る1). 著者らは, 院内で調剤されたキョウニン水含有製 剂 (Table 1) が，患者の手に渡ってから，服用までの 間の保存条件等により，その有効成分とされる Man の 経時变化状態を馝念した. したがって，Manの測定は pharmacokinetics, bioavailability の研究, 究明等の目 的で重要と思われる. Man の測定に関しては, クロマ トグラフ的な分離, 分析が有効と考えられる. Manにア ンモニアを作用させるとベンズアルデヒドとシアン化ア

* 岐阜県多治見市前畑町 5-161；5-161, Maehatacho, Tajimi-shi, Gifu, 507 Japan
ソモニウムを定量的に遊離すること1)から，遊離したべ ンズアルデヒドを高速液体クロマトグラフィー (HPLC) により分析を試みたので報告する.

\section{実 験 方 法}

\section{1. 試薬および試液}

特に述べるもの以外はすべて市販の試薬 (特級) を 用いた。内部標準含有抽出液: $\alpha$-(o-tolylazo)- $\boldsymbol{\beta}$-naphthylamine (東京化成)をデシケータ（シリカゲル） で 4 時間乾燥し，その約 $100 \mathrm{mg}$ を精科して，䣫酸エチ ルを加えて溶解後, 正確に $100 \mathrm{ml}$ とする. その $10 \mathrm{ml}$ を 正確にとり, 酢酸エチルを加え正確に $30 \mathrm{ml}$ とする $(0.3$ $\mathrm{mg} / \mathrm{ml}$ ). メタノール: 液体クロートグラフ用（和光純 薬), Man (Aldrich), ベンズアルデヒド (和光純薬), 院内調剤キョウニン水含有製剤 (Table 1) を使用した.

\section{2. 装国および器具}




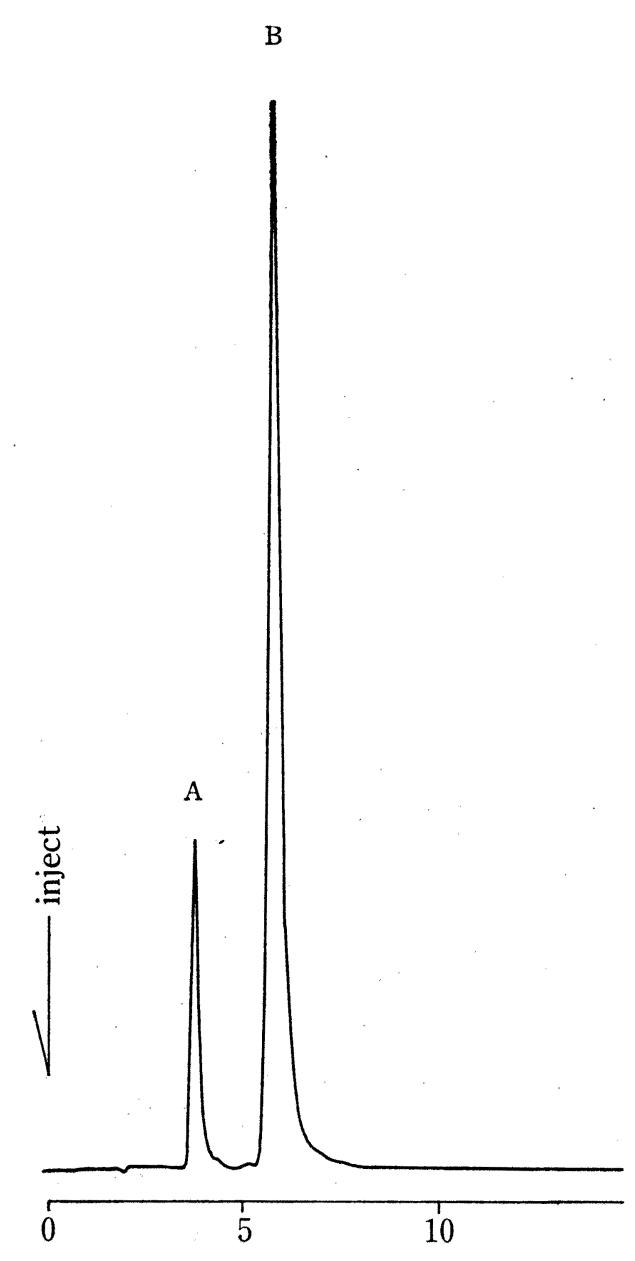

Retention time (min)

Fig. 1. Liquid Chromatogram of Benzaldehyde Produced Corresponding to Mandelonitrile Extracted from Apricot Kernel Water Oparating conditions :

Paking; Fine pack SIL $\mathrm{C}_{18}$

Column; $250 \times 4.6 \mathrm{~mm} \mathrm{I.D.}$

Mobile phase ; $\mathrm{MeOH}: \mathrm{H}_{2} \mathrm{O}(7: 3 \mathrm{v} / \mathrm{v})$

Flow pate $; 0.8 \mathrm{ml} / \mathrm{min}$

Detection ; $242 \mathrm{~nm}$

$A$ : benzaldehyde,

B : $\alpha$-(o-tolylazo) $-\beta$-naphthylamine (i. s.)

波長可変 UV モニタ一付日本分光 Twincle 高速液体 クロマトグラフ，ハミルトン製マイクロシリンジ，およ び KUBOTA KS-3000P 遠心機を使用して行った。

3. 液体クロマトグラフィー条件

カラム; 日本分光 Finepak SIL $C_{18}, 4.6 \mathrm{mmI}$. D. $\times$
$250 \mathrm{~mm}$. 溶解液; メタノール: 水 $(7: 3 \mathrm{v} / \mathrm{v})$. 流速; $0.8 \mathrm{ml} / \mathrm{min}$. 測定吸收波長; $242 \mathrm{~nm}$. 測定温度; 室温.

\section{4. 定国法}

陚料の一定量 $(0.5 \mathrm{ml})$ を $10 \mathrm{ml}$ の遠沈管にとり, $1 \%$ 塩酸ヒドロキシルアミン溶液 $0.3 \mathrm{ml}$ を加え, 室温で 10 分間放置する. 次に，アセトン $0.2 \mathrm{ml}$ を加光，振り混 ぜ 5 分間放置し， $10 \%$ アンモニア試液 $0.3 \mathrm{ml}$ を加えて再 度 5 分間放置する. 次に食塩を飽和させ, 内部標準含有 抽出液 $2 \mathrm{ml}$ で抽出し, 必要ならば遠心分離する. 内部 慓準含有抽出液層の一定量を HPLC に付す. 内部標準 物質に対するピーク面積比を求め, 別に作成した検量線 よりベンズアルデヒドの量を算出する.

\section{結果および教察}

\section{1. 吸収スペクトル}

液体クロマトグラフィ一条件の溶離液組成比, メタ, ール:水 $(7: 3 \mathrm{v} / \mathrm{v})$ にベンズアルデヒドを溶解させ, 吸収スペクトルを描いたところ $242 \mathrm{~nm}$ 付近に最大吸収 がみられたので，検出波長を $242 \mathrm{~nm}$ とした.

\section{2. 溶䨼液の検时}

ベンズアルデヒドのクロマト挙動を Finepak SIL C18 カラムを使用して，メタノール・水，エタノール・ 水, アセトニトリル・水のそれぞれの条件下で検討 し た. その結果, 保持時間, 分離条件の点からメタノール ・水 $(7: 3 \mathrm{v} / \mathrm{v})$ とした.

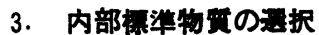

定量法操作について，まず内部標準物質を入れないで 全操作を行い，Table 2 に示した物質のピークが出ない ことを確認後, 内部標準物を選択した. その結果, 保持 時間，拉よび安定性の点から $\alpha$-(o-tolylazo)- $\beta$-naphthylamine を採用した. なおこの際得られたクロマト グラムを Fig. 1 に示す.

\section{4. 検胃線および㭢度}

河合の報告2) を準用して，ベンズアルデヒドの検量線 を定量法条件下で作成した，その結果，ベンズアルデヒ ド濃度が $0.5-5.0 \mu \mathrm{g} / \mathrm{ml}$ の濃度範囲 で, 相 関 係数が 0.9993 と良好な結果を示した $(n=10)$ ．また本法の測定 精度をベンズアルデヒド $1.0 \mu \mathrm{g} / \mathrm{ml}$ 溶液を用い，標準添 加法を併用し検討した結果, 11回の試行で変動係数 0.67 \%といら值を得た.

\section{5. アルカリ漕度の検期}

河合の報告2)を準用して Man の定量的分解に用いる アルカリ濃度について，キョウニン水を用い検討した。 すなわち, キョウニン水 $10 \mathrm{ml}$ を精秤し, 水 $50 \mathrm{ml}, \exists$ ウ化カリウム試液 $1 \mathrm{ml}$ およびアンモニア試液（または水 
Table : 1

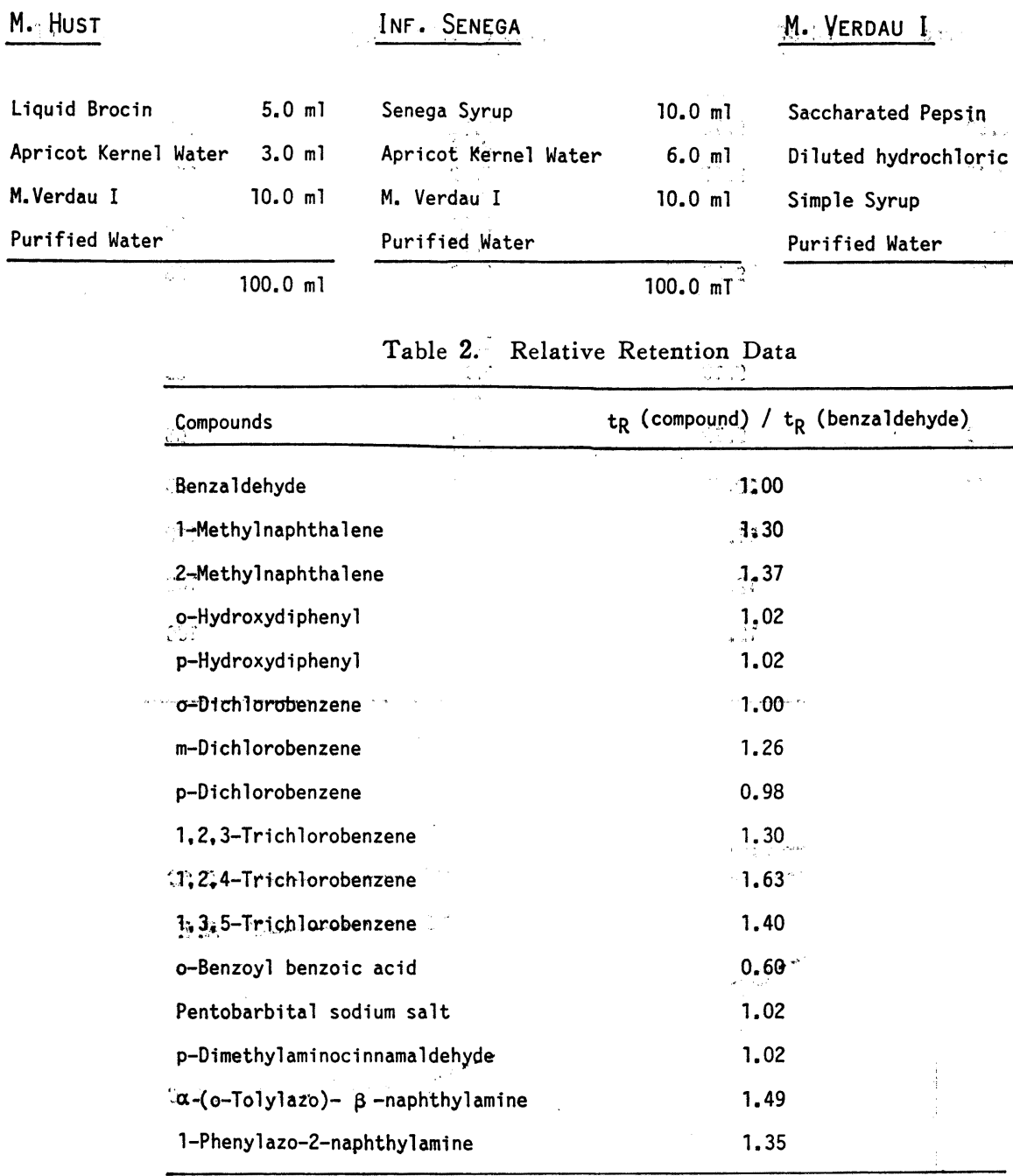

酸化ナトリウム試液) の一定量を加えて, 持続する黄色 の混濁を生じるまで $0.1 \mathrm{~N}$ 硝酸銀で滴定した（Table 3).

ここで10\%\%アンモニア試液（5.88M） $0.5 \mathrm{ml}$ を加え た滴定検液の $\mathrm{pH}$ は約 $9.74 て ゙ あ り ， 1 \mathrm{~N}$ 水酸化ナトリウ ム $0.19 \mathrm{ml}$ を加えた場合の $\mathrm{pH} 9.79$ とほほ等しい值を 示す. しかし, Table 3 からは, 10\%アンモニア試液 $0.5 \mathrm{ml}$ で Man の分解率が100\%であるのに対し, 1N水酸化ナトリウム試液 $0.19 \mathrm{ml}$ では Man の分解率が65 \%と低值を示した. 1N-水酸化ナトリウム $1.00 \mathrm{ml}$ を加 えた条件で, Man の分解率100\%を示すのは Man の分 解が定量的に進行していることを示している. また，こ の場合の $\mathrm{pH}$ は 11.81 であった. 水酸化ナトリウム濃度
をさらに高くしても，硝酸銀滴定量に変化はなく，10\% アンモニア試液 $0.5 \mathrm{ml}$ 添加の場合と一致していた. し たがって，Manの分解に関与する要素は, $\mathrm{pH}$ で表現さ れるアルカリ性の強度ではなく, $\mathrm{NH}_{3}$ のロンペアが有 効であることが示唆された.すなわち， $\mathrm{pH}$ 濃度が高く ならなくてもアンモニア試液を使用した場合は, 水酸化 ナトリウム試液を使用した場合と異なり, 反応は進行す ることが示唆された。

\section{6. 本法のキョウニン水含有製郕分析への応用}

Table 1 に示した院内製剤である M. Hust および Inf.Senega を $5^{\circ} \mathrm{C}$ 冷暗所, 室温, $50^{\circ} \mathrm{C}$ のそれぞれの保 存条件下で35日間放置し, 各製剤中のキョウニン主成分 の変動を Fig.2，Fig.3 にそれぞれ示した. Fig.2， 
Table 3. Activity of Basic Compounds on Decomposition of Mandelonitrile

\begin{tabular}{|c|c|c|c|c|}
\hline $\begin{array}{l}\text { Amount of } \\
\text { added }\end{array}$ & $\begin{array}{l}\text { basic compound } \\
(\mathrm{ml})\end{array}$ & $\begin{array}{c}\text { PH of test solution } \\
\text { (measured) }\end{array}$ & $\begin{array}{c}\text { Amount of } 0.1 \mathrm{~N} \mathrm{AgNO}_{3} \\
(\mathrm{ml})\end{array}$ & $\begin{array}{l}\text { Rate of composition of } \\
\text { mandelonitrile }(\%)\end{array}$ \\
\hline \multirow[t]{6}{*}{$10 \% \mathrm{NH}_{3}$} & 0.50 & 9.74 & $\begin{array}{l}2.02 \\
2.04\end{array}$ & 100 \\
\hline & 0.40 & 9.67 & $\begin{array}{l}2.02 \\
2.00\end{array}$ & 100 \\
\hline & 0.30 & $9: 55$ & $\begin{array}{l}2.01 \\
2.00\end{array}$ & 100 \\
\hline & 0.20 & 9.37 & $\begin{array}{l}1.93 \\
1.90\end{array}$ & 96 \\
\hline & 0.166 & 9.29 & $\begin{array}{l}1.77 \\
1.80\end{array}$ & 88 \\
\hline & 0.10 & 9.10 & $\begin{array}{l}1.20 \\
1.20\end{array}$ & 59 \\
\hline \multirow[t]{5}{*}{ IN NaOH } & 0.19 & 9.79 & $\begin{array}{l}1.31 \\
1.30\end{array}$ & 65 \\
\hline & 0.50 & 10.51 & $\begin{array}{l}1.62 \\
1.64\end{array}$ & 80 \\
\hline & 1.00 & 11.81 & $\begin{array}{l}2.02 \\
2.01\end{array}$ & 100 \\
\hline & 1.50 & 12.21 & $\begin{array}{l}2.05 \\
2.00\end{array}$ & 100 \\
\hline & 2.00 & 12.38 & $\begin{array}{l}2.02 \\
2.05\end{array}$ & 100 \\
\hline
\end{tabular}

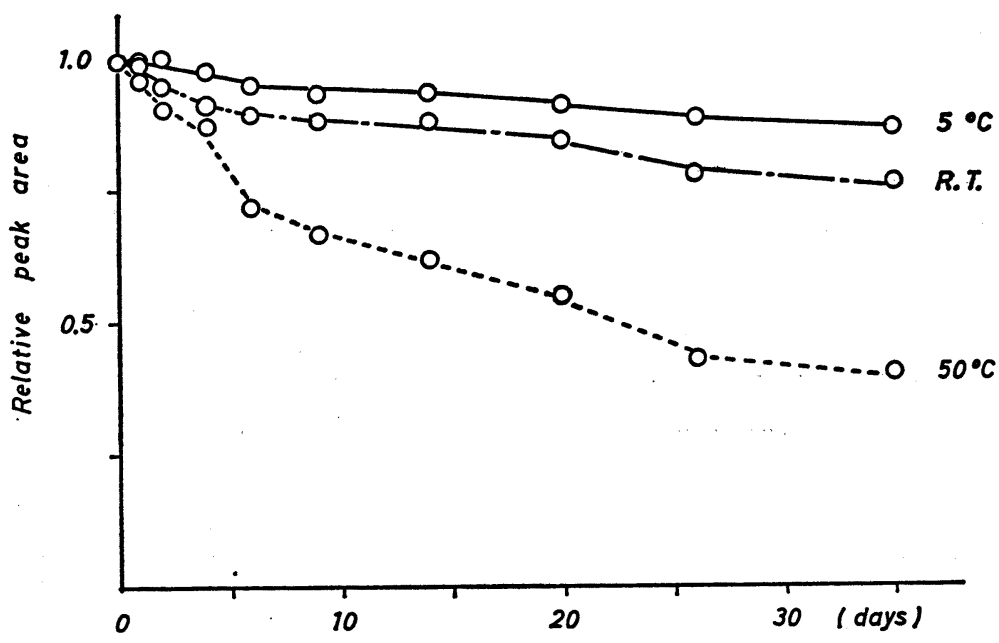

Fig.2. Relationship of Temperature and Benzaldehyde Concentration in M.Hust

Fig.3 からみられるように，50Cで35日間保存条件下で はキョウニン水主成分が初期濃度の50\%程度であった.

以上のように, HPLCによるキョウウンン水中 Man の 定量法を確立した. 着色合剤, すなわち，今回検討した よらなキョウニン水，セネガシロップ，ブロチン液など のような試料では, 局方の Liebig-Deniges 法による滴 定1ではその適用が困難であったが，今回検討したHPLC では他の成分との分離, 保持もよく, かつ着色合剂にも
適用可能であり, 本法の有用性が示唆された. さらに, 今回実験の対象としたキョウニン水含有製剤の各保存条 件下では, 温度の高い条件下と比較して, 温度の低い条 件下においてキョウニン水主成分 Man の分解率が低か ったことから,キョウニン水含有製剤の保存には, 特に 夏季の場合, 冷暗所保存が必要と思われた。

謝辞 温かいご助言を賜わりました岐阜薬科大学分析 学教室助教授, 河合 聡、先生に深謝いたします。 


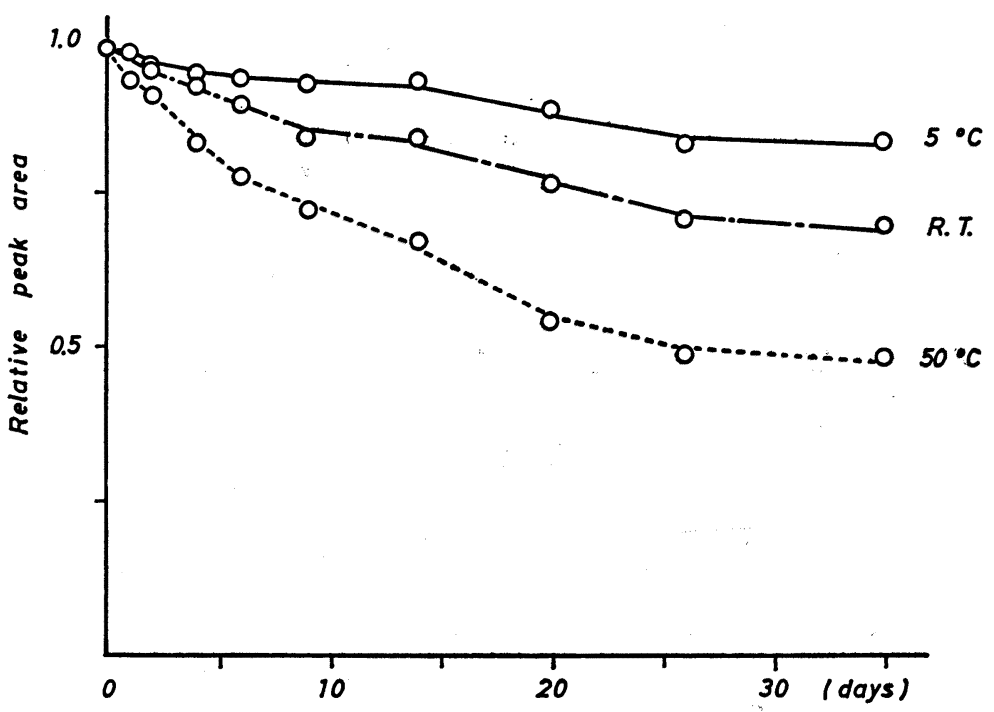

Fig. 3. Relationship of Temperature and Benzaldehyde Concentration in Inf. Senega

\section{引用 文 献}

1）“第十改正日本薬局方解説書”，広川费店，東京，
$1981, \mathrm{D}-230$.

2) 河合 聡, 宇治昭子, 大野武男：分析化学, 28, 193 (1979). 